\title{
Analysis of Sensitometry in Radiographic Films using Optical Density Measurement
}

\author{
Oladotun A. Ojo, Peter A. Oluwafisoye, and Charles O. Chime
}

\begin{abstract}
The sensitivity of radiographic films is an important factor to the clarity and accuracy of $X$-ray exposure to patients during treatment or diagnostic periods. It is therefore important to do a thorough analysis of the sensitivity of the radiographic film before and after exposure to enhance the Quality Assurance (QA) and the Quality Control (QC), of the exposure procedures. The optical densities (OD) of each film was measured, with a densitometer model MA 5336, made by GAMMEX. These values were then converted to the absorbed dose ( $\mathrm{X}$ mGy), which is the amount of dose absorbed by each patient. The optical density versus the dose curve, followed the expected pattern, showing a good prediction from the General model, that the films employed in the exposures were of good quality and standard. Hence the optical density versus dose sensitometric curves depicts the outcome of the various films sensitivity after an exposure to the $\mathrm{X}$-ray radiation through the patients.
\end{abstract}

Index Terms - Absorbed, exposure, density, dose, optical, radiation, radiographic, sensitivity, sensitometric.

\section{INTRODUCTION}

X-ray examinations can lead to an increased radiation dose to the patient. To reduce this risk, quality assurance methods are very essential. In the processing and production of X-ray films, quality assurance is required for quality images. It is needful to maintain a high level of film processing quality, and so a daily check of the film processor is required. A sensitometer is used to expose a grey wedge with 21 steps on a test strip of the X-ray film. After developing the film, a densitometer will be used to measure the density of various steps of the grey wedge. Errors in the film processing such as changes in speed and contrasts of the exposed film are detected by this method [1].

One way of knowing practically a two (2-D) relative dose distribution in vast portions of radiographic films with high spatial resolution, is to employ radiographic films. With a good arrangement, the inclusion of film affects an insignificant distortion of distribution of the dose. These properties make film dosimetry useful technique for dose verification in a phantom for evaluating the accuracy of dose calculations performed by a treatment planning system [2], [3], to verify advanced conformal techniques applying intensity modulated beams [4], [5], and for quality control tests of specific properties of radiation beams [6].

For film dosimetry, radiation interaction with film is quantified by relating the dose to the blackening of the film

Published on August 24, 2020.

O. A. Ojo, Osun State University, Nigeria

(corresponding e-mail: dotun4realoj ${ }^{\circledR}$ gmail.com)

P. A. Oluwafisoye, Institute of Science Laboratory, Nigeria.

(e-mail: paoluwafisoye@ ${ }^{\circledR}$ ahoo.com)

C. O. Chime, University of Benin Teaching Hospital, Nigeria.

(e-mail: charleschime@yahoo.com) (optical density, OD), yielding the sensitometric curve. The necessity and purpose of the sensitometric curve should display clearly the sensitivity of a particular film for example, to radiation exposed to it. However, some of the parameters that determines the value of the optical density measured after film exposure in photon beams like, photon energy, irradiated conditions, composition of the emulsion, processing of the film and characteristics of the film scanner (densitometer).

A difficulty of variable like the phantom energy spectrum cannot be totally avoided, which is bound to change for a particular photon beam quality with both depth and field size due to the variation in phantom scatter and beam hardening. Some past works have shown large differences in magnitude of the depth - field size effect. These conflicting data might be related to differences in film exposure techniques such as irradiating the film parallel or perpendicular to the control beam axis [7]. Good dosimetric results can, however, be obtained if films from the same batch are irradiated with small to moderate field sizes (up to about $15 \mathrm{~cm} \times 15 \mathrm{~cm}$ ), at moderate depths (up to about $15 \mathrm{~cm}$ ), using a single calibration curve for a $10 \mathrm{~cm} \times 10 \mathrm{~cm}$ field [7].

\section{MATERIALS AND METHODS}

Adult radiographic films, totaling thirty (30), already irradiated from patient exposure to X-ray were collected as samples. The optical densities (OD), of the films were measured, using a densitometer, model 5336. The measured optical densities were used to estimate the X-ray radiation absorbed dose to the patients at the radiological center. The radiographs were from different examinations, namely, Skull (PA, PAL L., LAT R., LAT L.) and Mandible (LAT R., LAT L., PA). The following abbreviations were adapted for the purpose of this study:

PA: Posterior Anterior

AP: Anterior Posterior

LAT. RT: LATERAL RIGTH

LAT. LT: LATERAL LEFT

MAND: MANDIBLE

$\mathrm{X}$ : Absorbed X-ray dose

NOD: Net Optical Density

MOD: Mean Optical Density

$D_{\text {MOD }}$ : Mean Optical Density

OD or D: Optical Density

$\mathrm{OD}_{1}, \mathrm{OD}_{2}, \mathrm{OD}_{3}, \mathrm{OD}_{4}$ and $\mathrm{OD}_{5}$ : Measured Optical Densities

S/N: Film Serial Number.

TABLE I: FEATURES OF THE DENSITOMETER [8] 


\begin{tabular}{ll}
\hline \multicolumn{1}{c}{ GAMMEX) } & \\
\hline Range & 0 to 4.0 optical density \\
\hline Accuracy & \pm 0.02 density \\
\hline Reproducibility & \pm 0.01 density \\
\hline Warm up time & None \\
\hline Measuring area & 2mm diameter and 1mm diameter \\
\hline Power supply & Four rechargeable AA NiCad batteries, \\
& 4.8 V total rated at $600 \mathrm{mAh}$ (included $)$ \\
\hline Battery charger & SE $30-45(115 \mathrm{VAC})$ or SE $-30(230$ \\
\hline Charge time & VAC) 50 to $60 \mathrm{~Hz}$ \\
\hline Size & Approximately 14 hours \\
& $5.08 \times$ X 7.46 X $17.8 \mathrm{~cm}$ \\
\hline Weight & $(2 \times 2.9 \times 7$ in $)$ \\
\hline
\end{tabular}

A film densitometer, model MA 5336 for the measurement of optical density was used. The light source / detector assembly is driven in finite incremental steps and resolution over the entire scanning area to ensure precise positioning with a high degree of repeatability [9]. The film densitometer is a simple to use peripheral device for the measurement of the blackening density film exposed to ionizing radiation. Since X-ray image on the film is a black and white image with various blackening densities, the densitometer accepts standard X-ray films [9].

The optical densities of each radiograph were measured repeatedly five times at different spots on each image of the film as optical densities $\mathrm{OD}_{1}, \mathrm{OD}_{2}, \mathrm{OD}_{3}, \mathrm{OD}_{4}$ and $\mathrm{OD}_{5}$. The average of the five optical densities was then taken to obtain the MOD. The optical densities were converted to the absorbed X-ray radiation doses $\mathrm{X}$, in milli gray (mGy), which is the amount of $\mathrm{X}$-ray radiation dose that each patient was exposed to. The mean absorbed dose, range of absorbed dose, standard deviation, kurtosis, first and third quartiles were also calculated for the samples. The blackening of the film after X-ray radiation exposure is expressed in terms of its optical density as [10]:

$$
D=\log _{10}\left(\frac{I_{o}}{I}\right)
$$

Where $I_{o}$ and $I$ is the light intensities before and after passing the exposed film material. Optical density is a numerical value indicating the degree of blackening on an $\mathrm{X}$-ray radiographic film. The correlation between the optical density and the maximum number of sensitized grains results in a relation between the optical density and the absorbed dose X. Thus:

$$
D=D_{\max }\left[1-e^{-k X}\right]
$$

where,

$$
D_{\max }=4
$$

(this is the maximum measurable OD obtainable with the densitometer) [10],

$k=9.36$ ( $k$ is a conversion constant) [10].

Therefore, Equation (2) for the measured optical density becomes:

$$
D=4\left[1-e^{-9.36 X}\right]
$$

Solving Equation (3) for the absorbed X-ray radiation dose $\mathrm{X}$, gives:

$$
X=\left(-\frac{1}{9.36}\right) \log _{e}\left(1-\frac{D_{M O D}}{4}\right) \ldots \ldots \ldots
$$

Equation (4) was used to convert the measured optical densities of the radiographs to absorbed $\mathrm{X}$-ray radiation dose, in milli gray (mGy).

\section{RESULTS AND DISCUSSIONS}

The results obtained in this work are presented in Tables II, III and IV for the radiographic examinations for the values of OD, $X$, NOD and MOD.

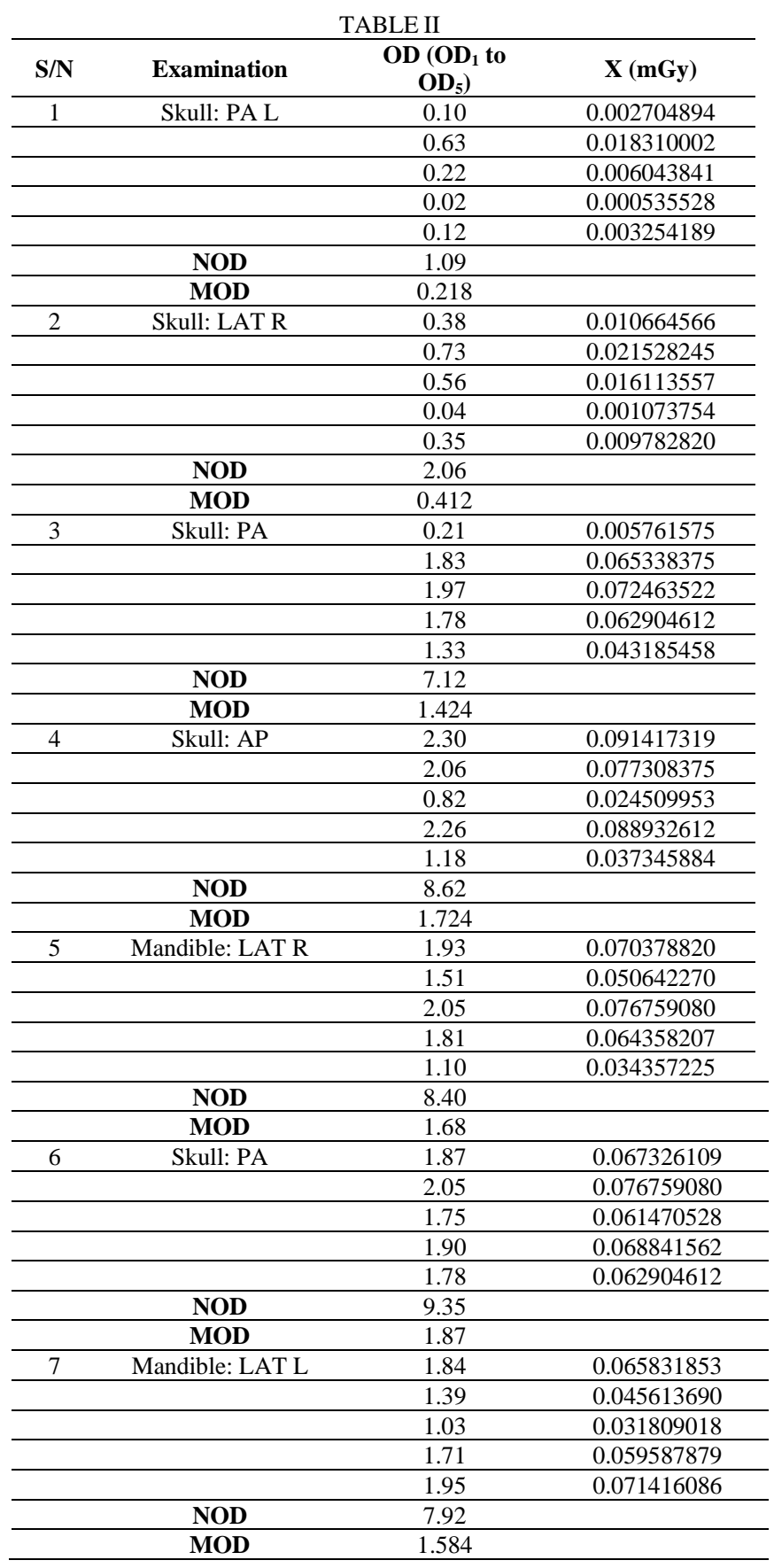

TABLE III

$\begin{array}{llll}\text { S/N } & \text { Examination } & \text { OD }\left(\text { OD }_{1} \text { to } \text { OD }_{5}\right) & \text { X (mGy) }\end{array}$




\begin{tabular}{|c|c|c|c|}
\hline 1 & Mandible: LAT L & 2.35 & 0.094606739 \\
\hline & & 2.38 & 0.096567117 \\
\hline & & 1.77 & 0.062424442 \\
\hline & & 2.41 & 0.098564139 \\
\hline & & 2.36 & 0.095256209 \\
\hline & NOD & 11.27 & \\
\hline & MOD & 2.254 & \\
\hline \multirow[t]{7}{*}{2} & Mandible: LAT R & 2.02 & 0.075127940 \\
\hline & & 2.30 & 0.091417319 \\
\hline & & 2.15 & 0.082383410 \\
\hline & & 2.37 & 0.095909652 \\
\hline & & 2.27 & 0.089548392 \\
\hline & NOD & 11.11 & \\
\hline & MOD & 2.222 & \\
\hline \multirow[t]{7}{*}{3} & Skull: PA & 1.58 & 0.053688763 \\
\hline & & 1.33 & 0.043185458 \\
\hline & & 1.98 & 0.072991116 \\
\hline & & 1.99 & 0.073521329 \\
\hline & & 2.16 & 0.082962478 \\
\hline & NOD & 9.04 & \\
\hline & MOD & 1.808 & \\
\hline \multirow[t]{7}{*}{4} & Skull: PA & 1.78 & 0.062904612 \\
\hline & & 1.96 & 0.071938521 \\
\hline & & 1.86 & 0.066825698 \\
\hline & & 1.86 & 0.066825698 \\
\hline & & 2.04 & 0.076212595 \\
\hline & NOD & 9.50 & \\
\hline & MOD & 1.90 & \\
\hline \multirow[t]{7}{*}{5} & Mandible: PA & 1.91 & 0.069351527 \\
\hline & & 1.90 & 0.068841562 \\
\hline & & 1.78 & 0.062904612 \\
\hline & & 1.76 & 0.061946420 \\
\hline & & 1.66 & 0.057280281 \\
\hline & NOD & 9.01 & \\
\hline & MOD & 1.802 & \\
\hline \multirow[t]{7}{*}{6} & Skull: PA & 2.80 & 0.128629573 \\
\hline & & 2.37 & 0.095909652 \\
\hline & & 2.14 & 0.081807465 \\
\hline & & 2.30 & 0.091417319 \\
\hline & & 2.37 & 0.095909652 \\
\hline & NOD & 11.98 & \\
\hline & MOD & 2.396 & \\
\hline \multirow[t]{7}{*}{7} & Mandible: LAT L & 1.86 & 0.066825698 \\
\hline & & 1.50 & 0.050214063 \\
\hline & & 2.07 & 0.077860508 \\
\hline & & 1.50 & 0.050214063 \\
\hline & & 1.73 & 0.060525057 \\
\hline & NOD & 8.66 & \\
\hline & MOD & 1.732 & \\
\hline \multirow[t]{7}{*}{8} & Mandible: LAT R & 1.40 & 0.046023816 \\
\hline & & 1.67 & 0.057737831 \\
\hline & & 1.87 & 0.067326109 \\
\hline & & 1.40 & 0.046023816 \\
\hline & & 1.05 & 0.032530896 \\
\hline & NOD & 7.39 & \\
\hline & MOD & 1.478 & \\
\hline \multicolumn{4}{|c|}{ TABLE IV } \\
\hline S/N & Examination & $\mathrm{OD}\left(O \mathrm{OD}_{1}\right.$ to $\left.O D_{5}\right)$ & X (mGy) \\
\hline \multirow[t]{7}{*}{1} & Skull: PA & 1.98 & 0.07299112 \\
\hline & & 1.91 & 0.06935153 \\
\hline & & 2.07 & 0.07786051 \\
\hline & & 1.51 & 0.05064227 \\
\hline & & 1.81 & 0.06435821 \\
\hline & NOD & 9.28 & \\
\hline & MOD & 1.856 & \\
\hline \multirow[t]{7}{*}{2} & Mandible: LAT L & 1.77 & 0.06242444 \\
\hline & & 1.47 & 0.04893964 \\
\hline & & 1.01 & 0.03109198 \\
\hline & & 1.51 & 0.05064227 \\
\hline & & 1.75 & 0.06147053 \\
\hline & NOD & 7.51 & \\
\hline & MOD & 1.502 & \\
\hline 3 & Mandible: LAT R & 1.57 & 0.05324819 \\
\hline & & 1.45 & 0.04809840 \\
\hline & & 1.23 & 0.03925716 \\
\hline
\end{tabular}

\begin{tabular}{|c|c|c|c|}
\hline & & 1.23 & 0.03925716 \\
\hline & & 1.36 & 0.04439268 \\
\hline & NOD & 6.84 & \\
\hline & MOD & 1.368 & \\
\hline \multirow[t]{7}{*}{4} & Skull: PA & 2.35 & 0.09460674 \\
\hline & & 2.38 & 0.09656712 \\
\hline & & 2.44 & 0.10059920 \\
\hline & & 2.41 & 0.09856414 \\
\hline & & 2.36 & 0.09525621 \\
\hline & NOD & 11.94 & \\
\hline & MOD & 2.388 & \\
\hline \multirow[t]{7}{*}{5} & Mandible: LAT R & 2.02 & 0.07512794 \\
\hline & & 2.30 & 0.09141732 \\
\hline & & 1.77 & 0.06242444 \\
\hline & & 2.37 & 0.09590965 \\
\hline & & 2.27 & 0.08954839 \\
\hline & NOD & 10.73 & \\
\hline & MOD & 2.146 & \\
\hline \multirow[t]{7}{*}{6} & Mandible: LAT L & 1.58 & 0.05368876 \\
\hline & & 1.33 & 0.04318546 \\
\hline & & 2.15 & 0.08238341 \\
\hline & & 1.99 & 0.07352133 \\
\hline & & 2.16 & 0.08296248 \\
\hline & NOD & 9.21 & \\
\hline & MOD & 1.842 & \\
\hline \multirow[t]{7}{*}{7} & Mandible: LAT L & 1.55 & 0.05237247 \\
\hline & & 1.70 & 0.05912235 \\
\hline & & 1.22 & 0.03887216 \\
\hline & & 1.33 & 0.04318546 \\
\hline & & 1.42 & 0.04684882 \\
\hline & NOD & 7.22 & \\
\hline & MOD & 1.444 & \\
\hline \multirow[t]{7}{*}{8} & Mandible LAT R & 1.90 & 0.06884156 \\
\hline & & 1.55 & 0.05237247 \\
\hline & & 1.71 & 0.05958788 \\
\hline & & 1.97 & 0.07246352 \\
\hline & & 1.88 & 0.06782888 \\
\hline & NOD & 9.01 & \\
\hline & MOD & 1.802 & \\
\hline \multirow[t]{7}{*}{9} & Skull: LAT L & 2.36 & 0.09525621 \\
\hline & & 1.67 & 0.05773783 \\
\hline & & 2.07 & 0.07786051 \\
\hline & & 1.95 & 0.07141609 \\
\hline & & 2.21 & 0.08590585 \\
\hline & NOD & 10.26 & \\
\hline & MOD & 2.052 & \\
\hline \multirow[t]{7}{*}{10} & Skull: LAT R & 2.28 & 0.09016774 \\
\hline & & 2.32 & 0.09268168 \\
\hline & & 2.27 & 0.08954839 \\
\hline & & 0.49 & 0.01396136 \\
\hline & & 2.37 & 0.09590965 \\
\hline & NOD & 9.73 & \\
\hline & MOD & 1.946 & \\
\hline \multirow[t]{7}{*}{11} & Skull: PA & 1.68 & 0.05819735 \\
\hline & & 1.79 & 0.06338695 \\
\hline & & 1.67 & 0.05773783 \\
\hline & & 1.62 & 0.05546943 \\
\hline & & 1.17 & 0.03696770 \\
\hline & NOD & 7.93 & \\
\hline & MOD & 1.586 & \\
\hline \multirow[t]{7}{*}{12} & Skull: PA & 1.97 & 0.07246352 \\
\hline & & 1.93 & 0.07037882 \\
\hline & & 2.10 & 0.07953424 \\
\hline & & 1.91 & 0.06935153 \\
\hline & & 1.91 & 0.06935153 \\
\hline & NOD & 9.82 & \\
\hline & MOD & 1.964 & \\
\hline 13 & Mandible: LAT L & 1.24 & 0.03964356 \\
\hline & & 1.73 & 0.06052506 \\
\hline & & 1.22 & 0.03887216 \\
\hline & & 1.29 & 0.04159677 \\
\hline & & 1.29 & 0.04159677 \\
\hline & NOD & 6.77 & \\
\hline & MOD & 1.354 & \\
\hline 14 & Mandible: LAT R & 1.25 & 0.04003135 \\
\hline & & 1.88 & 0.06782888 \\
\hline
\end{tabular}




\begin{tabular}{cccc}
\hline & & 1.87 & 0.06732611 \\
\hline & 1.94 & 0.07089619 \\
\hline & & 1.70 & 0.05912235 \\
\hline & NOD & 8.64 & \\
\hline $15 \quad$ MOD & 1.728 & \\
\hline & Skull: PA & 0.39 & 0.010960106 \\
\hline & 0.15 & 0.004083463 \\
\hline & 0.25 & 0.006895141 \\
\hline & 0.06 & 0.001614705 \\
\hline & 0.10 & 0.002704894 \\
\hline & 0.95 & \\
\hline & NOD & 0.19 & \\
\hline MOD & &
\end{tabular}

In the Tables, the measured optical densities were seen to vary across the radiographic images during the measurements. This was expected, as the density of the tissues, thickness of the tissues and thickness of the bones varies for each radiographs. The average of the measured OD's is thus taken to be Mean Optical Density (MOD). Also, the estimated doses for the radiographs and occurrence of variations in the estimated absorbed doses can be seen, for the same reason stated above. These results in Tables were in good agreement with the Nigerian Basic Ionizing Radiation Regulation (NBIRR) [11] and the International Commission on Radiological Protection (ICRP) [12]. The Figures represent the plots and the results of the OD's against the $\mathrm{X}$, for the radiographs, to depict their various sensitometry properties, from a curve fitting using the MATLAB.

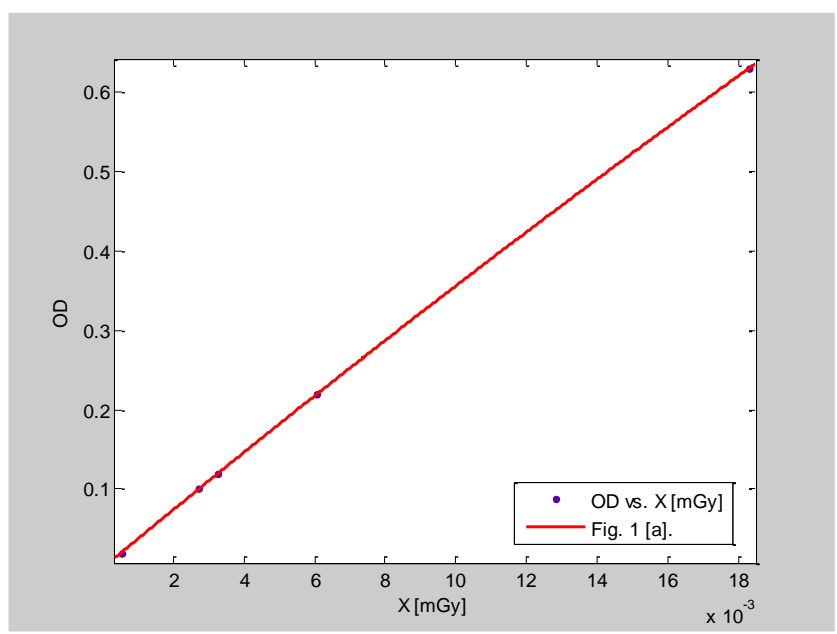

Fig. 1 a. Skull PA L sensitometric curve of the radiographic film in Table II

Results:

General model:

$\mathrm{f}(\mathrm{x})=\operatorname{Dmax} *\left[1-\exp \left(-\mathrm{k}^{*} \mathrm{x}\right)\right]$

Coefficients (with $95 \%$ confidence bounds):

$$
\begin{aligned}
& \operatorname{Dmax}=\quad 4(3.998,4.001) \\
& \mathrm{k}=\quad 9.36(9.356,9.364)
\end{aligned}
$$

Goodness of fit:

SSE: $1.112 \mathrm{e}-011$

R-square: 1

Adjusted R-square: 1

RMSE: 1

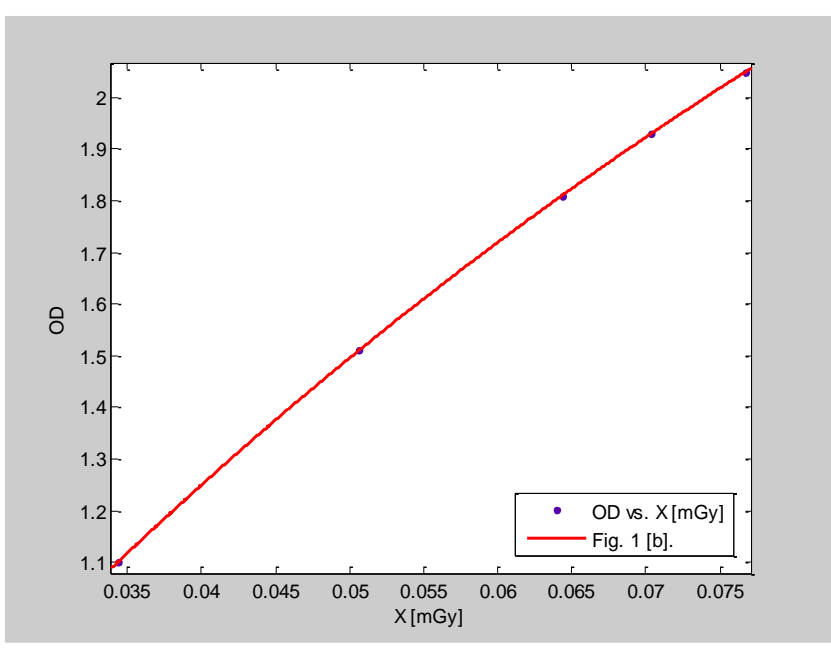

Fig. 1 b. Mandible LAT L sensitometric curve of the radiographic film in Table II.

Results:

General model:

$f(x)=\operatorname{Dmax} *\left[1-\exp \left(-k^{*} x\right)\right]$

Coefficients (with $95 \%$ confidence bounds):

$$
\begin{aligned}
& \text { Dmax }=\quad 4(4,4) \\
& \mathrm{k}=\quad 9.36(9.36,9.36)
\end{aligned}
$$

Goodness of fit:

SSE: $1.108 \mathrm{e}-016$

R-square: 1

Adjusted R-square: 1

RMSE: $6.077 \mathrm{e}-009$

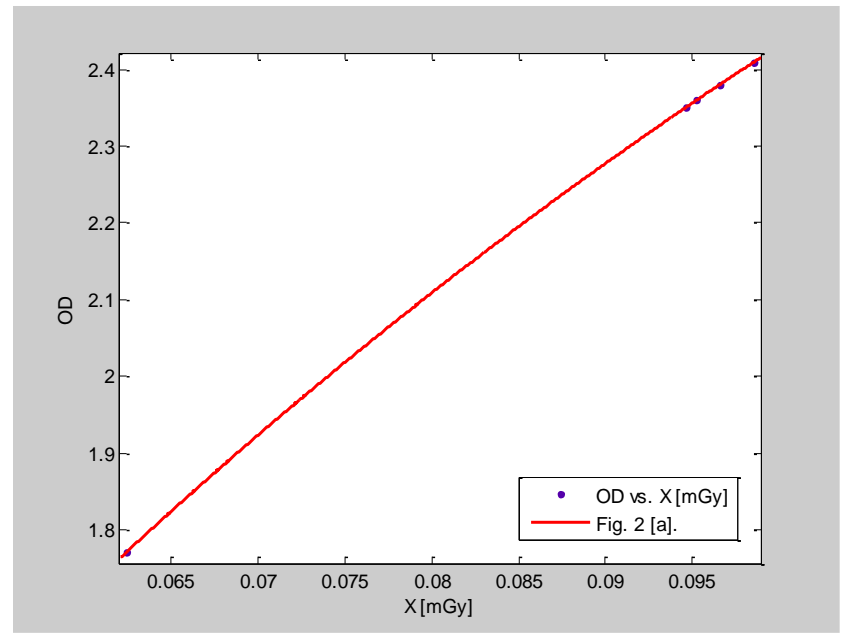

Fig. 2 a. Mandible LAT L sensitometric curve of the radiographic film in Table III.

Results:

General model:

$$
\mathrm{f}(\mathrm{x})=\operatorname{Dmax} *\left[1-\exp \left(-\mathrm{k}^{*} \mathrm{x}\right)\right]
$$

Coefficients (with $95 \%$ confidence bounds):

$$
\begin{aligned}
& \text { Dmax }= \\
& \mathrm{k}=\quad 4(4,4)
\end{aligned}
$$

Goodness of fit:

SSE: $3.375 \mathrm{e}-012$

R-square: 1

Adjusted R-square: 1

RMSE: $1.061 \mathrm{e}-006$ 


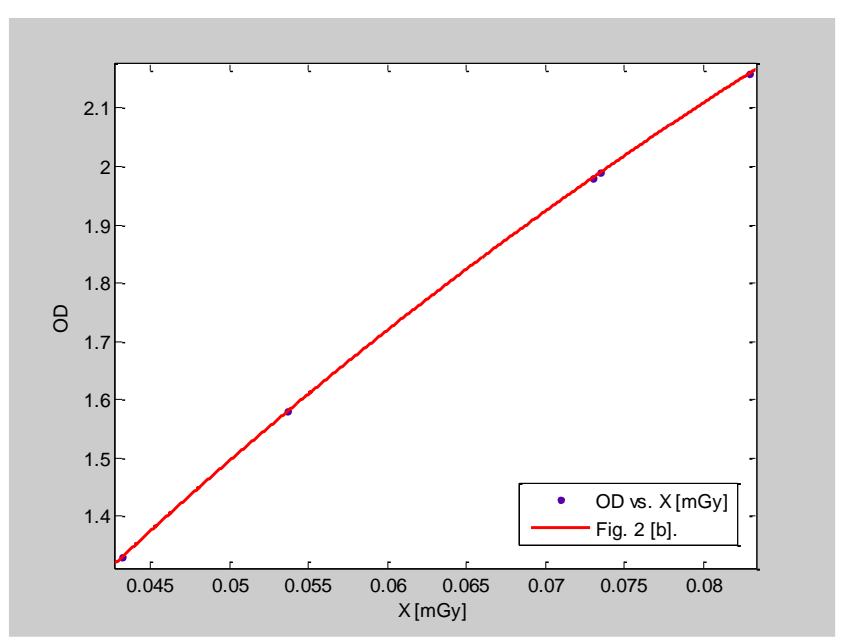

Fig. 2 b. Skull PA sensitometric curve of the radiographic film in Table III.

Results:

General model:

$$
\mathrm{f}(\mathrm{x})=\operatorname{Dmax} *\left[1-\exp \left(-\mathrm{k}^{*} \mathrm{x}\right)\right]
$$

Coefficients (with $95 \%$ confidence bounds):

$$
\begin{aligned}
& \text { Dmax }= \\
& \mathrm{k}=\quad 4(4,4)
\end{aligned}
$$

Goodness of fit:

SSE: $4.624 \mathrm{e}-016$

R-square: 1

Adjusted R-square: 1

RMSE: $1.242 \mathrm{e}-008$

The Figures represents the sensitometric curves from the different examinations, exposed to the X-ray radiation. The curves follows the expected pattern for the OD vs Dose trend. The General model depicts coefficients with $95 \%$ confidence bounds, there is a range for the maximum optical density Dmax, as also the range for the conversion constant k. The Goodness of fit was a good expected Sum of Square Errors (SSE's), minimal enough, R-square and the Adjusted $\mathrm{R}$-square were as expected, as this shows that a value of 1 or close to 1 projects good exposure factors and safe amount of doses for the X-ray radiation in use, ensuring the optimal sensitivity of the films used.

\section{CONCLUSION}

The optical density versus dose sensitometric curves depicts the outcome of the various films sensitivity after exposure of the patient to X-ray radiation. In the plots, the response of the films to the radiation is seen to be linear in terms of the optical density against the dose, as shown in the Figures. The linearity means that the films have a high sensitivity to the $\mathrm{X}$-ray radiation, either at minimum or maximum values.

The results of the model as shown a good fit with each of the curves linearity. These values are within the range that is expected of an exact fit. The analysis of film response to Xray radiation using the optical density measurement approach can be used to do a Quality Assurance (QA) and Quality Control (QC) in terms of any type of radiographic film sensitivity.

\section{ACKNOWLEDGMENT}

The authors will like to thank the staffs of the Radiological center, Benin City Edo State, Nigeria, for making available the radiographs to be used for the purpose of this research work.

\section{REFERENCES}

[1] NUCLEMED BV (2020). Darklight Duo Combination Sensitometer NUCLMED BV, t Hoog Stuk 27, B - 8800 Roeselare, Belgium. Registered company BE 0435.002.834.

[2] N.A.M, van Bree, M.H Idzes, H.Huizenga, and B.J Mijnheer (1994). "Film dosimetry for radiotherapy treatment planning verification of a 6MV tangential breast irradiation, "Radiother, Oncol. 31, 251 - 255.

[3] R.L. stern, B.A. Fraass, A. Gerhardsson, D.L McShan, and K.L. Lam (1992). "Generation and use of measurement - based 3-D dose distribution for 3 - D dose calculation verification, "Med. Phys. 19, $165-173$.

[4] A Frazier, M.Du, J. Wong, F.Vicini, R. Taylor, C. Yu, R. Matter, A. Martinez, and D. Yan (1995). "Dosimetric evaluation of the confirmation of the multileaf collimator to irregularity shaped fields, "Int. J. Radiat. Oncol., Biol., Phys. 33, 1229 - 1238.

[5] J.M. Galvin, A.R. Smith, R.D. Moeller, R.L. Goodman, W.D. Powlis, J. Rubenstein, L.J. Solin, B.Michael, M. Needham and C.J. Huntzinger (1992). "Evaluation of multileaf collimator de for a photon beam, "Int. J. Radiat. Oncol., Biol., Phys. 23, 789 - 801.

[6] X. Wang, S. Spirou, T. Losasso, J. Stein, C.S. Chui and B. Mohan (1996). "Dosimetric verification of intensity - modulated fields," Med. Phys. 23, $317-327$.

[7] L.J. Bos, C. Danciu, C. Cheng, M. J.P. Brugmans, A. Horst, A. Minken and B.J. Mijnheer (2002). Interinstitutional variations of sensitometric curves of radiographic dosimetric films. Med. Phys. 29(8), $1772-1780$.

[8] GAMMEX (2016). Film Densitometer Peripheral Technical manual Model 5336. GAMMEX Middleton, WI, USA.

[9] Scarlat F, Scarsoreamu A, Oane M, Mitru E, Badita E (2008). Determinationof Absorbed Dose Using a Dosimetric Film. IX Radiation Physics \& Protection Conference, 15 - 19 November, Nasir City, Egypt, 313 - 321.

[10] Artur T. (2003). Determination of Absorbed X-ray Radiation Dose in X-ray Diagnostics and Imaging. J. Med. Sci. 1 (2): 31 - 36.

[11] NBIRR (Nigeria Basic Ionizing Radiation Regulation) (2003).

[12] ICRP (International Commission on Radiological Protection) (1996). Radiological Protection and Safety in Medicine, Publication 73 (Oxford and New York: Pergamon Press).

Oladotun A. Ojo is a Lecturer and Researcher at Osun State University, department of Physics. He holds a Ph.D. in Biophysics / Medical Physics / Biomechanics. His research interests are in the areas of radiation dosimetry, biomedical and medical imaging, DNA sequencing, RNA sequencing, radiation oncology, bioinformatics, radiation medicine, and telemedicine.

Peter A. Oluwafisoye is a Director and Researcher at Education Training and Inspectorate, Nigerian Institute of Science Laboratory Technology Federal Ministry of Science and Technology, Ibadan, Oyo State, Nigeria. He holds a Ph.D. degree in Health and Radiation Physics / Medical Physics. His research interests are in the areas of radiation dosimetry, radiation oncology, biomedical and medical imaging, radiation medicine, environmental safety.

Charles O. Chime is a senior Radiographer and Imaging Scientist at the Radiology department of the University of Benin Teaching Hospital (UBTH), Benin City, Edo State,

Nigeria. He holds a Bachelor of Radiography and Medical Imaging. His research interests are medical imaging, biomedical imaging and diagnostic radiology. 